\title{
BMJ Open Systematic review of the association between dietary acid load, alkaline water and cancer
}

\author{
Tanis R Fenton, ${ }^{1,2}$ Tian Huang ${ }^{2,3}$
}

To cite: Fenton TR, Huang T. Systematic review of the association between dietary acid load, alkaline water and cancer. BMJ Open 2016;6: e010438. doi:10.1136/ bmjopen-2015-010438

- Prepublication history and additional material is available. To view please visit the journal (http://dx.doi.org/ 10.1136/bmjopen-2015010438).

Received 4 November 2015 Revised 18 March 2016 Accepted 21 March 2016

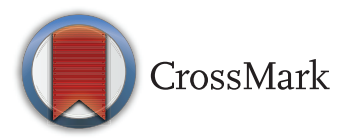

${ }^{1}$ Department of Community Health Sciences, O'Brien Institute for Public Health, Alberta Children's Hospital Research Institute, University of Calgary, Calgary, Alberta, Canada

${ }^{2}$ Nutrition Services, Alberta Health Services, Calgary, Alberta, Canada

${ }^{3}$ Faculty of Agriculture, Life and Environmental Sciences, Edmonton Clinic Health Academy, University of Alberta, Edmonton, Alberta, Canada

Correspondence to Dr Tanis R Fenton; TFenton@ucalgary.ca

\section{ABSTRACT}

Objectives: To evaluate the evidence for a causal relationship between dietary acid/alkaline and alkaline water for the aetiology and treatment of cancer.

Design: A systematic review was conducted on published and grey literature separately for randomised intervention and observational studies with either varying acid-base dietary intakes and/or alkaline water with any cancer outcome or for cancer treatment.

Outcome measures: Incidence of cancer and outcomes of cancer treatment.

Results: 8278 citations were identified, and 252 abstracts were reviewed; 1 study met the inclusion criteria and was included in this systematic review. No randomised trials were located. No studies were located that examined dietary acid or alkaline or alkaline water for cancer treatment. The included study was a cohort study with a low risk of bias. This study revealed no association between the diet acid load with bladder cancer (OR=1.15: $95 \% \mathrm{Cl} 0.86$ to $1.55, \mathrm{p}=0.36$ ). No association was found even among long-term smokers (OR=1.72: $95 \% \mathrm{Cl} 0.96$ to $3.10, p=0.08$ ).

Conclusions: Despite the promotion of the alkaline diet and alkaline water by the media and salespeople, there is almost no actual research to either support or disprove these ideas. This systematic review of the literature revealed a lack of evidence for or against diet acid load and/or alkaline water for the initiation or treatment of cancer. Promotion of alkaline diet and alkaline water to the public for cancer prevention or treatment is not justified.

\section{INTRODUCTION}

The general public is being encouraged by the lay press that to prevent cancer; they are persuaded to assess the acidity of their urine and/or saliva as an assessment of the acidity of their body and then to modify their diets accordingly. ${ }^{1-7}$ The alkaline diet, or acid-ash diet, is being promoted based on the claims that modern diets acidify the body ${ }^{1-11}$ causing diseases including cancer, osteoporosis and cardiovascular disease. ${ }^{1-12}$ The alkaline diet is also promoted for conditions including diabetes and hypertension. Promoters of this diet claim that changing

\section{Strengths and limitations of this study}

Broad search of both the published and unpublished literature on both alkaline diets and alkaline water was conducted for studies to include in this systematic review.

- We located only one observational study that fit the inclusion criteria.

- The objective, to determine if evidence of a causal relationship exists between dietary acid or alkaline and the etiology of cancer and/or the treatment of this disease, was defined a priori.

- Explicit reproducible methodology.

- Assessed the included study's validity, ie risk of bias, using a quality checklist.

food choices to more 'alkaline' selections prevents all of these conditions ${ }^{1-9} 11$ and has the ability to treat cancer once it has been developed. ${ }^{5101213}$ This diet is based on the concept that mineral components of foods make the body acidic, alkaline or neutral. ${ }^{14}$

The alkaline diet is designed to provide more alkaline ions after metabolism, based on the acid-ash hypothesis developed over 100 years ago. ${ }^{15}$ The acid-ash hypothesis suggests that to achieve a more alkaline load, one must consume more fruit and vegetables with only a moderate intake of protein. While marketing of this diet implies that the diet changes will raise systemic $\mathrm{pH}$, a wellconducted randomised trial of these diet changes altered only systemic $\mathrm{pH}$ by 0.014 units, while the urine $\mathrm{pH}$ increased by 1.02 units. $^{16}$ This study reveals that diet changes can alter urine $\mathrm{pH}$ but does not change blood $\mathrm{pH}^{16}$ Furthermore, the fact that the effect of phosphorus on calcium metabolism is opposite to that was predicted by the hypothesis ${ }^{17}$ raises questions about the validity of the hypothesis. Additionally, a review of the body of evidence regarding the acid-ash/alkaline hypothesis for bone health found that the hypothesis is not supported and there is no evidence that altering the diet acid load improves bone health. ${ }^{18}$ 
The marketing of the alkaline diet promotes not only a diet, but also the sale of related supplements and water alkaliniser machines through almost every media medium, including websites, books and videos. ${ }^{1-6} 8$ In our experience, patients with cancer are approached by salespeople who are promoting water alkalinisers as a way to treat their cancer. Studies suggest that a substantial and growing number of patients use the internet to obtain health information, ${ }^{19} 20$ which may not be innocuous. Oncologists report that internet use by patients with cancer contributes to confusion and anxiety among patients with cancer. ${ }^{20}$

There is some evidence that some cancer cells and tumours grow well in an acidic environment in the laboratory. ${ }^{21}{ }^{22}$ While the alkaline diet is being promoted to correct the acid state that the modern diet creates, the American Institute of Cancer Research and the Canadian Cancer Society have stated that the body tightly regulates systemic $\mathrm{pH}$ and food choices will only affect urine $\mathrm{pH}$ and not body acidity. ${ }^{23}{ }^{24}$ Studies show that while urine $\mathrm{pH}$ changes in response to diet changes, blood $\mathrm{pH}$ does not. ${ }^{1625}$ As acid/base forming potential of foods does alter urinary $\mathrm{pH},{ }^{16}{ }^{25}$ cancers of the urinary tract may be an important focus in investigating claims of the alkaline diet to prevent and treat cancer.

As far as we are aware, no systematic review has been done to evaluate the evidence for an association between dietary acid and/or alkaline, or the effectiveness of alkaline water, for the aetiology or treatment of cancer. The purpose of this systematic review is to conduct an extensive search of the published and unpublished literature to determine whether evidence of a causal relationship exists between dietary acid or alkaline and the aetiology of cancer and/or the treatment of this disease.

\section{METHODS}

\section{Eligibility criteria}

Randomised interventions and observational human studies of acid-base intakes of diet, supplemental salts to change systemic $\mathrm{pH}$ (such as potassium bicarbonate or potassium citrate) and consumption of alkaline water, with cancer outcomes (both aetiology and treatment), were sought. No language or publication date restrictions were imposed. Human participants of all ages and backgrounds were considered. Studies with no original research (narrative reviews, editorials) and non-human studies were excluded from this review.

\section{Literature search}

Two reviewers conducted independent literature searches, one with the assistance of a librarian (J.P.), in an attempt to find all human studies of the ash-acid diet hypothesis or an alkaline diet with any type of cancer as the outcome. Studies were identified through search text words and Medical subject headings: diet, dietary, acid, acidic, alkaline, acid-base, acid-base equilibrium, acid-ash, net acid excretion (NAE), 'potential renal acid load, water, cancer, neoplasm' (see online supplementary file). For published literature, databases searched included Ovid MEDLINE, PubMed, Cochrane Register of Clinical Trials, CINAHL and Embase up to April 2015. No limits were applied to searches, and studies reported in all languages were considered. In an effort to include all available studies, reference lists for the located articles were also reviewed. For grey literature, Current Controlled Trials, Canadian Cancer Trials, Google, and Google Scholar were manually searched up to April 2015.

Both reviewers examined the article titles for relevance to the topic and potential fit to the inclusion criteria independently, with the plan to use discussion and resolution by reaching consensus of any differences in assessments. When the title was not clear regarding the potential fit, both reviewers reviewed the abstracts. For abstracts which suggested relevance, the full text of the article was reviewed. Both researchers extracted data independently. There was no indication of unpublished data from the search, so authors were not contacted.

Data extracted included exposures to estimates of acid generated from diet, among humans, and with the outcome of any cancer.

Results with $\mathrm{p}$ values $<0.05$ were considered to be statistically significant, and relative risk $>2.0$ with no plausible residual confounding were considered clinically relevant. ${ }^{26}$ We used the Newcastle-Ottawa Scale to assess the included study for risk of bias. ${ }^{27}$

\section{RESULTS}

\section{Description of studies}

A total of 8278 citations were identified, and 252 abstracts were reviewed for potential fit; only 1 study met the inclusion criteria ${ }^{28}$ and was included in this systematic review. There were no disagreements about articles' fit to the inclusion criteria between the reviewers. The literature search also located a systematic review that found no evidence for the alkaline diet ${ }^{29}$ and two narrative reviews discussing the acid-ash/alkaline diet and cancer. ${ }^{30}$ No relevant unpublished studies were found.

The systematic review, published in 2014, reported finding four articles on the alkaline diet and cancer in a Google search but it did not report findings from these articles or their references. ${ }^{29}$

The two narrative reviews did not include any human studies of an association between diet acid/alkaline and cancer. The narrative review by Robey ${ }^{31}$ concluded: "there are numerous systemic pathways affected by diet-induced acidosis that may be cancer promoting, but a causal role is poorly defined". The review by Lee and Shen ${ }^{30}$ suggested a post hoc analogy between the traditional Chinese medicine concepts of yin and yang with the acid/alkaline diet but did not cite any studies of the acid/alkaline diet and cancer.

The included study, by Wright $e t a l,{ }^{28}$ was a prospective cohort study, nested within the $\alpha$-Tocopherol, 
Table 1 Included study

\begin{tabular}{|c|c|c|c|c|c|c|}
\hline Study & Population & Outcome & Results & $\begin{array}{l}\text { Study } \\
\text { design }\end{array}$ & $\begin{array}{l}\text { Potential modifiers } \\
\text { or confounders }\end{array}$ & Other risk of bias \\
\hline $\begin{array}{l}\text { Wright } \\
\text { et a }{ }^{88}\end{array}$ & $\begin{array}{l}29133 \text { male } \\
\text { residents of } \\
\text { southwestern } \\
\text { Finland, aged } 50- \\
69 \text { years who } \\
\text { smoked } 5 \text { or more } \\
\text { years }\end{array}$ & $\begin{array}{l}\text { Relative } \\
\text { risk of } \\
\text { bladder } \\
\text { cancer }\end{array}$ & $\begin{array}{l}\text { The relative risk } \\
\text { (RR) for bladder } \\
\text { cancer was } 1.15 \\
(\mathrm{Cl} 0.86 \text { to } 1.55 \text {, } \\
\mathrm{p}=0.38) \text {, } \\
\text { suggesting that } \\
\text { urine } \mathrm{pH} \text { is not a } \\
\text { major risk factor } \\
\text { for bladder } \\
\text { cancer }\end{array}$ & $\begin{array}{l}\text { Prospective } \\
\text { cohort study }\end{array}$ & $\begin{array}{l}\text { Energy intake, age, } \\
\text { number of cigarettes } \\
\text { smoked daily, number } \\
\text { of years of smoking, } \\
\alpha \text {-tocopherol and } \\
\beta \text {-carotene } \\
\text { supplementation, BMI, } \\
\text { total fluid intake, } \\
\text { education level, place } \\
\text { of residence, } \\
\text { pack-years of smoking, } \\
\text { smoking inhalation, } \\
\text { smoking cessation, } \\
\text { calcium, magnesium } \\
\text { and/or potassium } \\
\text { supplements } \\
\text { Effect modification by } \\
\text { smoking duration, } \\
\text { smoking dose, total } \\
\text { fluid intake, BMl and } \\
\text { intervention group was } \\
\text { evaluated in stratified } \\
\text { analysis }\end{array}$ & $\begin{array}{l}\text { Used renal NAE } \\
\text { based on a validated } \\
\text { formula based on } \\
\text { nutrient intake and } \\
\text { anthropometric } \\
\text { information to } \\
\text { estimate true urine } \\
\mathrm{pH}\end{array}$ \\
\hline
\end{tabular}

BMI, body mass index; NAE, net acid excretion; RR, relative risk.

$\beta$-Carotene Cancer Prevention Study, a randomised controlled trial (table 1). This study examined the diet acid load and the occurrence of bladder cancer. The exposure used in this study was an estimate of renal NAE, based on dietary intakes and anthropometrics. No studies were found that examined any other cancer or neoplastic outcomes with dietary acid, alkalinity, alkaline water, the use of an alkaline diet, alkaline water or change of the diet acid load for cancer treatment.

Wright et $a l^{28}$ examined the relationship between diet-estimated renal NAE using a food frequency questionnaire (and measured height and weight for the estimation of urinary organic acid excretion) with the risk of bladder cancer in a large cohort of 27096 male smokers. ${ }^{28}$ The relative risk estimate for bladder cancer was 1.15 (CI 0.86 to $1.55, \mathrm{p}=0.38$ ) for individuals in the most acidic versus the least acidic NAE quintile as assessed in a multivariate proportional hazards model, a not statistically significant relationship. These researchers also tested whether acidic urine was associated with an increased risk of bladder cancer in a subset of longterm smokers. Among men who smoked for more than 45 years, there was a non-significant, adjusted relative risk of bladder cancer of 1.72 (CI 0.96 to $3.10, \mathrm{p}=0.08$ ) with higher NAE levels.

\section{Risks of bias assessment}

Overall, we rated the Wright study ${ }^{28}$ as having a low risk of bias since it warranted a score of 7 out of a possible 9 on the Newcastle-Ottawa Scale. ${ }^{27}$ We reduced the score from a full $9 / 9$ since food frequency questionnaires are imperfect descriptions of exposure to nutrients, ${ }^{32}$ and due to possible residual confounding. Additionally, since the study by Wright $e t a l^{28}$ was a prospective observational study, this study had the strength of temporality, since the exposure (estimated urine acidity) preceded the outcome (bladder cancer risk). The study relied on estimated renal NAE to determine urine acidity, which could potentially result in misclassification of individuals.

\section{DISCUSSION}

This systematic review, based on only one relevant observational study, did not find support for the acid-ash hypothesis which suggests that acid from the diet causes or contributes to cancer development. ${ }^{1-6}$ The GRADE working group recommends that any associations from observational data are weak evidence unless the results show at least a twofold risk with no concerns about confounding, or a fivefold risk with narrow CIs when there are remaining concerns about bias. ${ }^{26}$ The estimates of effect between the diet acid load and bladder cancer in this study were not statistically significant, and the estimates of effect were low relative to the GRADE guidelines.

The included Wright study ${ }^{28}$ had strengths of having a low risk of bias on the Newcastle-Ottawa $\mathrm{Scale}^{27}$ and temporality between the exposure (NAE) and bladder cancer risk and controlled for several potentially 
cofounding variables. These study strengths provide support that the study reached accurate conclusions.

Our thorough literature search did not locate any studies of this acid/alkali hypothesis for any other forms of cancer or cancer treatment. Additionally, our literature search failed to locate any studies that evaluated whether alkaline water has a role in prevention or treatment of cancer. Thus, there is a lack of support for any advice to the public about the acid-ash hypothesis, the alkaline diet and/or alkaline water and their relationships to cancer. By searching the published and unpublished literature for studies on this topic, we decreased the risk of publication bias. It is a limitation of this study that we located only one observational study.

Some review articles suggest that alterations in acidbase homeostasis in the tumour microenvironment are common in the pathology of cancer ${ }^{21} 22$ and that tumour interstitial fluid has a reduced buffering capacity compared with normal tissues, and along with high rates of production of metabolic end products, tumours may cause an acidic extracellular environment. ${ }^{22}$ Furthermore, cancer therapy may be influenced by $\mathrm{pH}$. Some in vitro and animal studies have suggested that metabolic alkalosis may be useful in enhancing some cancer treatment regimens. ${ }^{33}$

However, these in vitro examinations and animal studies of cancer cell behaviour are at the hypothesisgenerating phase and should not be extrapolated to human health. These cell culture studies do not address the questions or provide evidence regarding cancer aetiology or treatment. Studies have demonstrated that alkaline supplements ${ }^{25}$ or alkaline-promoting $\operatorname{diets}^{16}$ can alter urine $\mathrm{pH}$; however, they do not appreciably change overall systemic $\mathrm{pH}^{16}{ }^{25}$ Three studies of acid load interventions have measured both urine and blood $\mathrm{pH}$ changes as a result of various interventions, including changes in food intake, ${ }^{16}$ ingesting a bicarbonate salt ${ }^{25}$ or a phosphate salt. ${ }^{34}$ In each case, the urine $\mathrm{pH}$ increased markedly, from 0.2 to $1.2 \mathrm{pH}$ units, while blood $\mathrm{pH}$ did not changed minimally, by $0.01^{16}{ }^{25}$ to $0.02^{34} \mathrm{pH}$ units. The urine $\mathrm{pH}$ changes were $7.5^{34}$ to $177^{25}$ multiples of the blood $\mathrm{pH}$ changes. This comparison shows that kidneys are effective at excreting acid to maintain systemic $\mathrm{pH}$ balance and that urine $\mathrm{pH}$ does not provide a measurement of systemic $\mathrm{pH}$.

In spite of finding no human studies of alkaline water and cancer, our search did locate some studies of alkaline water; however, none of which supported the promotions that suggest alkaline water supports good health. We found outcomes from alkaline water included: in humans, inhibited gastric secretion, ${ }^{35}$ reduced gall bladder emptying, ${ }^{36}$ and toxic reactions; ${ }^{37}$ in rat pups: cardiac necrosis ${ }^{38}$ and growth restriction. ${ }^{39}$ Therefore, the promotion of alkaline water as health promoting is not supported by evidence.

There may be a safety concern involving eating an 'alkaline diet' and subsequently to increase urine $\mathrm{pH}$ of patients with bladder cancer. For instance, the influence of ciprofloxacin on human bladder cell lines suggests that the antiproliferative potential and antitumour effect of this drug may be superior at low urine $\mathrm{pH} .{ }^{40}$ Overall, safety considerations for increasing urinary $\mathrm{pH}$ in patients with bladder cancer undergoing certain cancer therapy treatments needs to be evaluated before the patients should undertake urine $\mathrm{pH}$ alterations.

Future study direction may focus on systematic reviews to examine the relationships between the alkaline diet and other health conditions. Several observational prospective studies have suggested a relationship between acid load and risk of type 2 diabetes ${ }^{41}{ }^{42}$ as well as hypertension. ${ }^{43}{ }^{44}$ However, in all three of these studies, the estimates of effect are of low magnitude, below the threshold of the relative risk of 2 , the minimum considered to indicate important associations. ${ }^{26}$ Furthermore, these studies had large sample sizes (1732-66 485); small significant $p$ values are likely in studies with large sample sizes even when there is no important effect. ${ }^{45}$ Other prospective studies have suggested a lack of association between the dietary acid load and risks of type 2 diabetes ${ }^{46}$ as well as hypertenstion. ${ }^{47}$ Furthermore, in observational studies, residual confounding is likely; ${ }^{26}$ many lifestyle variables are interrelated. Therefore, it is not recommended to suggest that the findings from such studies represent independent causal relationships. ${ }^{48}$ It must be noted that although observational studies are important in generating hypotheses, intervention studies are required to investigate and confirm associations between diet and disease.

The alkaline diet emphasises, to varying degrees, fresh fruits, vegetables, roots and tubers, and legumes with only a moderate protein intake. It is possible that some of these foods may have cancer-protective effects, not through their acidity/alkaline-promoting qualities but rather due to nutrient and non-nutritive compounds. A systematic review and meta-analysis of prospective studies show that a high intake of dietary fibre is associated with reduced risk of colorectal cancer. ${ }^{49}$ A review and meta-analysis of epidemiological research on physical activity, diet and adiposity found that a prudent dietary pattern of high intakes of fruits, vegetables, whole grains, legumes and fish appeared to be protective against breast cancer. ${ }^{50}$ However, the alkaline diet promotes the exclusion of many foods, and several of which contribute many beneficial nutrients and have health benefits.

\section{CONCLUSIONS}

Despite the promotion of the alkaline diet and alkaline water by the media and salespeople, there is almost no actual research to either support or disprove them. A systematic review of the literature revealed a lack of evidence of an association between a diet acid load or alkaline water for cancer risk and no studies alkaline treatment for cancer. Promotion of alkaline diet and alkaline water to the public for cancer prevention or treatment is not justified. 
Contributors TRF conceptualised and designed the study, and TH assisted in the conceptualisation and design of the study and drafted the initial manuscript. Both authors conducted comprehensive literature searches, conducted the analysis and interpretation of data for the work, reviewed and revised the manuscript, approved the final manuscript as submitted, and agree to be accountable for all aspects of the work.

Funding This research received no specific grant from any funding agency in the public, commercial or not-for-profit sectors.

\section{Competing interests None declared.}

Provenance and peer review Not commissioned; externally peer reviewed.

Data sharing statement No additional data are available.

Open Access This is an Open Access article distributed in accordance with the Creative Commons Attribution Non Commercial (CC BY-NC 4.0) license, which permits others to distribute, remix, adapt, build upon this work noncommercially, and license their derivative works on different terms, provided the original work is properly cited and the use is non-commercial. See: http:// creativecommons.org/licenses/by-nc/4.0/

\section{REFERENCES}

1. Young $\mathrm{RO}$. The $\mathrm{pH}$ miracle-balance your diet, reclaim your health. New York: Warner Books, 2002

2. Eating Veggies. 2012. http://eating-veggies.com (accessed $27 \mathrm{Jul}$ 2015).

3. Alkaline diet for Cancer. 2012. http://www.acidalkalinediet.com/ alkaline-diet-for-cancer (accessed 27 Jul 2015).

4. The Alkaline Guy. 2012. http://www.youtube.com/watch? $\mathrm{v}=2 \mathrm{H}$ toDmAtgt4 (accessed $27 \mathrm{Jul} 2015$ ).

5. Cancer Alkaline Diet is the Natural Cure. 2012. http://www.youtube. com/watch?v=ttm3q7kweL4 (accessed 27 Jul 2015).

6. Ohsawa G. Acid \& Alkaline-an overview of $\mathrm{pH}$ and human health 2012.

7. Corrett N. Le Regime Alcalin. Paris: Larousse, 2015.

8. Sebastian A, Frassetto L, Merriam R, et al. Estimation of the net acid load of the diet of ancestral preagricultural Homo sapiens and their hominid ancestors. Am J Clin Nutr 2002;76:1308-16.

9. Sebastian A, Morris RC. Improved mineral balance and skeletal metabolism in postmenopausal women treated with potassium bicarbonate. N Engl J Med 1994;331:279.

10. Marra J. Cause, cure, and cancer free: how I became a cancer free escapee. Pennsylvania: Sakura Publishing and Technologies, 2014

11. Jackson G. Alkaline foods for the alkaline diet: fell the $\mathrm{pH}$ miracle of the healthy $\mathrm{pH}$ diet. Createspace Independent Publishing Platform, 2014.

12. American Anit-Cancer Institute. http://www.americanaci.org/

13. Alkaline $\mathrm{pH}$ diet. 2012. http://www.alkalinephdiet.com/ alkaline-diet-for-cancer-patients/ (accessed 27 Jul 2015).

14. Dwyer J, Foulkes $\mathrm{E}$, Evans $\mathrm{M}$, et al. Acid/alkaline ash diets: time for assessment and change. J Am Diet Assoc 1985;85:841-5.

15. Sherman H, Gettler A. The balance of acid-forming and base-forming elements in foods, and its relation to ammonia metabolism. J Biol Chem 1912;11:323-38.

16. Buclin T, Cosma M, Appenzeller M, et al. Diet acids and alkalis influence calcium retention in bone. Osteoporos Int 2001;12:493-9.

17. Fenton TR, Lyon AW, Eliasziw M, et al. Phosphate decreases urine calcium and increases calcium balance: a meta-analysis of the osteoporosis acid-ash diet hypothesis. Nutr J 2009;8:41.

18. Fenton TR, Tough SC, Lyon AW, et al. Causal assessment of dietary acid load and bone disease: a systematic review \& meta-analysis applying Hill's epidemiologic criteria for causality. Nutr J 2011;10:41.

19. Pautler SE, Tan JK, Dugas GR, et al. Use of the internet for self-education by patients with prostate cancer. Urology 2001:57:230-3.

20. Helft PR, Hlubocky F, Daugherty CK. American oncologists' views of internet use by cancer patients: a mail survey of American Society of Clinical Oncology members. J Clin Oncol 2003;21:942-7.

21. McCarty MF, Whitaker J. Manipulating tumor acidification as a cancer treatment strategy. Altern Med Rev 2010;15:264-72.

22. Gillies RJ, Raghunand N, Garcia-Martin ML, et al. $\mathrm{pH}$ imaging. A review of $\mathrm{pH}$ measurement methods and applications in cancers. IEEE Eng Med Biol Mag 2004;23:57-64.

23. American Institute for Cancer Research. Questions about body $\mathrm{pH}$ and Cancer. 2012. http://www.aicr.org/press/health-features/ nutrition-wise/nw-questions-about-body-ph-and-cancer-mets-stevia. html (accessed 27 Jul 2015)
24. Canadian Cancer Society. 2012. http://www.cancer.ca/en/ prevention-and-screening/be-aware/cancer-myths-and-controversies/ an-alkaline-diet-and-cancer/?region=on (accessed 27 Jul 2015).

25. Maurer M, Riesen W, Muser J, et al. Neutralization of Western diet inhibits bone resorption independently of $\mathrm{K}$ intake and reduces cortisol secretion in humans. Am J Physiol Renal Physiol 2003;284: F32-40.

26. Guyatt $\mathrm{GH}$, Oxman AD, Sultan S, et al. GRADE guidelines: 9. Rating up the quality of evidence. J Clin Epidemiol 2011;64:1311-16.

27. Wells GA, Shea B, Connell DO, et al. The Newcastle-Ottawa Scale (NOS) for assessing the quality of nonrandomised studies in metaanalyses. 2000. http://www.ohri.ca/programs/clinical_epidemiology/ oxford.asp (accessed 15 May 2016).

28. Wright ME, Michaud DS, Pietinen $\mathrm{P}$, et al. Estimated urine $\mathrm{pH}$ and bladder cancer risk in a cohort of male smokers (Finland). Cancer Causes Control 2005;16:1117-23.

29. Huebner J, Marienfeld S, Abbenhardt C, et al. Counseling patients on cancer diets: a review of the literature and recommendations for clinical practice. Anticancer Res 2014;34:39-48.

30. Lee MM, Shen JM. Dietary patterns using traditional Chinese medicine principles in epidemiological studies. Asia Pac J Clin Nutr 2008;17(Suppl 1):79-81.

31. Robey IF. Examining the relationship between diet-induced acidosis and cancer. Nutr Metab (Lond) 2012;9:72.

32. Ioannidis JP. Implausible results in human nutrition research. BMJ 2013;347:f6698

33. Raghunand N, Gillies RJ. pH and chemotherapy. Novartis Found Symp 2001;240:199-211; discussion 265-8.

34. Krapf R, Glatz M, Hulter HN. Neutral phosphate administration generates and maintains renal metabolic alkalosis and hyperparathyroidism. Am J Physiol 1995;268:F802-7.

35. Drobnik M. [Evaluation of pharmacodynamic properties of medium-mineralized alkaline water designed for distribution as bottled natural mineral water]. Rocz Panstwowego Zakładu Hig 2000;51:379-84.

36. Gasbarrini G, Arienti V, Magri F, et al. [Effects of bicarbonatedalkaline water (Uliveto) on gastric and gallbladder emptying in normal subjects. Ultrasonic evaluation]. Minerva Med 1991;82:59-62.

37. Lendowski L, Färber H, Holy A, et al. Accidental contamination of a German town's drinking water with sodium hydroxide. Int $J$ Hyg Environ Health 2015;218:366-9.

38. Watanabe T, Kishikawa Y, Shirai W. Influence of alkaline ionized water on rat erythrocyte hexokinase activity and myocardium. J Toxicol Sci 1997;22:141-52.

39. Merne ME, Syrjänen KJ, Syrjänen SM. Systemic and local effects of long-term exposure to alkaline drinking water in rats. Int J Exp Pathol 2001:82:213-19.

40. Gurtowska N, Kloskowski T, Drewa T. Ciprofloxacin criteria in antimicrobial prophylaxis and bladder cancer recurrence. Med Sci Monit 2010;16:RA218-23.

41. Akter S, Eguchi M, Kuwahara K, et al. High dietary acid load is associated with insulin resistance: the Furukawa Nutrition and Health Study. Clin Nutr 2016;35:453-9.

42. Fagherazzi G, Vilier A, Bonnet F, et al. Dietary acid load and risk of type 2 diabetes: the E3N-EPIC cohort study. Diabetologia 2014;57:313-20.

43. Akter S, Eguchi M, Kurotani K, et al. High dietary acid load is associated with increased prevalence of hypertension: the Furukawa Nutrition and Health Study. Nutrition 2015;31:298-303.

44. Zhang L, Curhan GC, Forman JP. Diet-dependent net acid load and risk of incident hypertension in United States women. Hypertension 2009;54:751-5.

45. Higgins J, Green S, eds. Cochrane handbook for systematic reviews of interventions version 5.1.0. 2011. http://www.cochrane-handbook. org

46. Engberink MF, Bakker SJL, Brink EJ, et al. Dietary acid load and risk of hypertension: the Rotterdam study. Am J Clin Nutr 2012:95:1438-44.

47. $\mathrm{Xu} \mathrm{H}$, Jia T, Huang $\mathrm{X}$, et al. Dietary acid load, insulin sensitivity and risk of type 2 diabetes in community-dwelling older men. Diabetologia 2014:57:1561-8.

48. Ioannidis JP, Loy EY, Poulton R, et al. Researching genetic versus nongenetic determinants of disease: a comparison and proposed unification. Sci Transl Med 2009;1:7ps8.

49. Aune D, Chan DSM, Greenwood DC, et al. Dietary fiber and breast cancer risk: a systematic review and meta-analysis of prospective studies. Ann Oncol 2012;23:1394-402

50. Patterson RE, Cadmus LA, Emond JA, et al. Physical activity, diet, adiposity and female breast cancer prognosis: a review of the epidemiologic literature. Maturitas 2010;66:5-15. 